\title{
A COMPREHENSIVE REVIEW ON THE NANOCOMPOSITES OF GRAPHENE AND ITS DERIVATIVES IN THE APPLICATION OF SUPERCAPACITORS
}

\author{
P. Divya, A. Prithiba and R. Rajalakshmi* \\ Department of Chemistry, Avinashilingam Institute for Home Science and Higher Education for \\ Women, Coimbatore -641043,Tamil Nadu,India \\ *E-mail: rajivardhan@gmail.com
}

\begin{abstract}
The unique properties of Graphene-based nanocomposites have attracted numerous investigations in the field of materials science from supercapacitors to drug delivery applications. Graphene has received attention as a probe or electrode material source for supercapacitors because it consists of low electrical resistance, large electrolyte accessibility based on the larger surface area and chemical stability. The extra properties of graphene show some promising application such as optical electronics, composites and others. Supercapacitors are able to store more energy and can be fully charged / discharged at high speeds. This review has been mainly focused on the following points namely synthesis route of Graphene which consists of Bottom-Up and Top-Down approaches, are more difficult and hindering the massive production of graphene. We have also discussed the different techniques utilized for the synthesis of reduced graphene oxide namely thermally, hydrothermally, partially and electrochemically reduced graphene oxide and its electrochemical behavior. Analysis of these results inferred the specific capacitance in the range of 220,223.6, 225 and $230 \mathrm{~F} / \mathrm{g}$ (acid and neutral). The characterization of Graphene/Nanocomposites by RAMAN, FTIR, SEM and TEM analysis were also reviewed and found to be suitable for supercapacitors. In this review, the current development of the synthesis route of graphene oxide and its composites with future prospects is presented and discussed.
\end{abstract}

Keywords: Graphene, Nano composite, energy storage, pore structure, Supercapacitors

(C) RASĀYAN. All rights reserved

\section{INTRODUCTION}

Supercapacitors or ultracapacitors have attracted the attention of researchers globally due to high energy density, a long life-cycle and the compatibility with the environment compared to traditional batteries. It consists of electrodes, current collectors; an electrolyte and binder are the promising energy loading systems for the required applications of high energy density, high reliability, high power, long-term operating stability, size and weight, low cost, low level of heating, security, etc. Its power capabilities enable supercapacitors to link the space between the batteries of conventional and power necessities in terms of capacitors.

The need for intensive investigations is emphasized by highlighting the fact that current technologies fall short of the performance requirements expected for several existing as well as emerging applications. Understanding of molecular-level and interfacial processes that are fundamental to the working and failure of these systems, it is necessary that the systems be revisited with the aid of new analytical and characterization tools. Similarly, critical technology gaps must be addressed through new synthetic and processing strategies, engineering design and system modeling, and by pushing materials to their stability limits and tapping into new knowledge on Nano- and multi-functional materials. Graphene produced by expansion of graphene oxide (GO) thermally at elevated temperatures or at low temperatures relatively but under vacuum was used in the supercapacitor electrode. Reduced graphene oxide, a unique class of two-dimensional carbon nanostructures, has recently emerged as an outstanding candidate for the supercondensing material of electrode due to chemical stability, thermal stabilization, large electrical

Rasayan J. Chem., 12(1), 214-231(2019)

http://dx.doi.org/10.31788/RJC.2019.1215039

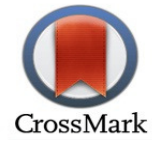




\section{RASĀYAN J. Chem.}

Vol. 12 | No. 1 |214 - 231| January - March | 201

conductivity, broad surface electrochemical window. In the electrochemical surface oxidation route, highquality graphene oxide was produced on the surface of the graphite $\operatorname{rod}^{1}$. Graphene oxide is synthesized through the chemical route where the presence of various oxygen functional groups is identified $^{2}$.Furthermore, the reduced GO (rGO) can be prepared on a huge scale at low cost. Several information is available on the rGO with dissimilar methods and the yields of rGO supercapacitors vary significantly in each case.

\section{Synthesis of Graphene Oxide}

Currently, the main graphene mass production methods focus on the solution-based redox chemical reaction. Graphite oxidation introduces a number of functional oxygen groups attached to its plane or its basal edges, which makes hydrophilic (GO) sheets to form steady aqueous or neutral colloids. However, graphite becomes an insulator gradually on the oxidation process, as a portion of hybrid planar $\mathrm{sp}^{2}$ geometry transformed into distorted $\mathrm{sp}^{3}$ hybridized geometry series that loses its perfect electronic properties. As a result, GO reduction is absolutely necessary to recover "lost" of the electrical conductivity for useful claims. Furthermore, the property of hydrophilic of the GO sheets enables anchoring of metal oxide nano particles in an rGO idea for the production of MO / RGO compounds with outstanding electrochemical performance. Numerous approaches have been established to produce physically and chemically reduced graphenes, such as electrochemical exfoliation, thermal growth from silicon carbide and chemical vapor deposition. Of these, the solution-based approach is considered the most favorable for large scale production. Low-cost supercapacitors made from ecologically approachable materials in use of flexible, portable, and single-use low-end products. Current promising production methods (LPE, graphene oxide and electrochemical pathway) have their benefits and limits, as tabulated in Table-2.

The exfoliation of GO can be chemically reduced, thermally, electrochemically or microwave assisted the process. Most of the reducing agents such as alkaline, ethylenediamine, hydrazine, $\mathrm{NaBH}_{4}$ and urea are toxic and explosive raise to serious protection and green problems. In addition, the possible stability involved in these processes to increase the dispersion of the GO due to their degradation in electronic properties. The capacitance, current density, area porosity of carbon from different ancestors for grapheme / nanocomposite precursors tabulated in Table-3.

\section{Synthesis route for Graphene}

By last forty years, several attempts have been made for the large-scale fabrication of pure and flawless graphene sheets. Recently, the epitaxial growth method in the carbide and the Chemical Vapor Deposition method have revealed promising results for the production of graphene ${ }^{3,4}$. Graphene can be produced via sulfur intercalated and thermal exfoliation method and it was used for the fabrication of modified electrode ${ }^{5}$.Several processes are classified in the "top-down" and "bottom-up" processes. The following process describes the synthetic paths for graphene.

\section{Top-down Approach}

This leads to an existing form of bulk material and the creation of the final product. This approach can be profitable, depending on the material used. Generally, it is limited to a laboratory scale and has limited quality control .In this approach, sheets of graphene are formed by altered separation, peeling, delamination or cleavage of graphite derivatives or graphite oxide (GO). However, this process includes a large investment and produces relatively low returns. Therefore, the use of mechanical processes have been complicated for the manufacture of high worth graphene without defects namely mechanical graphite exfoliation, functionalization, sonication, electrochemically exfoliation, excellent acid solution graphite, alkylation of graphene derivatives, chemically reduced of aqueous graphene oxide / organically treated. (IR), thermal exfoliation and chemically reduced of GO.

A detailed description of graphene synthesis with the method of exfoliation, functionalization and reduced together with its use in the manufacture of nano-composites has been broadly evaluated by Potts.et al. $(2011)^{6}$. Likewise, Daniel.et al. (2012) ${ }^{7}$ examined synthesis route of graphene with different sources using similar approaches were summarized. 


\section{Bottom-up Approach}

In this method, the epitaxial development using metallic products or substrates by CVD ${ }^{9,10,11}$ depending on the choice of chemical precursors, thermal degradation and disintegration of $\mathrm{SiC}^{8-13}$. Several other processes such as the discharge of $\operatorname{arc}^{14-16}$, chemical conversion ${ }^{16-18}$, reducing $\mathrm{CO}^{19}$, $\mathrm{CNT}$ decompression ${ }^{20-24}$ and self-organization of surfactants ${ }^{25-27}$ have it has also been tested for the graphene and their derivatives. Out of all these processes, the chemical vapor deposition and epitaxial growth, this produces large graphene sheets ${ }^{28}$ for the formation of large-scale graphene. Using methods of CVD and epitaxial, graphene sheets make their technique into the essential investigation with wide applications from electronic systems to polymer nanocomposites. Particularly, graphene oxide, chemically reduced graphite, reduced graphene oxide and thermally reduced GO are the ideal applicants for nanocomposite applications. The variation of reported specific capacitance and the porous material of carbon derived from several nanocomposite precursors based on graphene are represented in Fig.-3.

Although the bottom-up approach of the combination of graphene has fewer imperfections than the topdown approach, the activity and methods are much more difficult, hindering the massive generation. Even so, the most common way to synthesize graphene is an upside plan because it offers unbelievable potentials for increasing the atomic size, composition, shape, stability and graphene edge structure. The annual number of publications of the graphene / nanocomposite data reported is represented graphically in Fig.-4.

\section{Synthesis of Graphene-based Nanocomposites in the Application of Supercapacitors Methods of Synthesis of Graphene}

Most of the research studies conducted so far has focused on electronic mobility, which is determined by the dispersion of charged impurities and others inhomogeneity in graphene due to unique electronic properties ${ }^{29}$.In the subsequent paragraphs, we discuss the different techniques utilized for the synthesis of reduced graphene oxide. The various methods are illustrated below:

- Hydrothermally reduced graphene oxide

- Partially reduced graphene oxide

- Electrochemically reduced graphene oxide

- Thermally reduced graphene oxide

\section{Hydrothermally Reduced Graphene Oxide}

An environmentally simple and well-ordered hydrothermally dehydration pathway has been reported to convert GO into steady graphene solution ${ }^{30}$. The treated hydrothermally GO was characterized by UVvisible spectroscopy, atomic force microscopy, Raman spectroscopy, XPS and ${ }^{13} \mathrm{C}$ NMR spectra Compared to the hydrazine chemical reduction process, the current "water only" route has the benefit of eliminating the GO oxygen functional groups and restoring the aromatic structures. The result indicates that by controlling the hydrothermal temperatures, we can adjust the physical properties of graphene oxide and achieve the tunable optical limitation performance.

\section{Partially Reduced Graphene Oxide}

Graphene oxide is partially reduced, what is known as partially reduced graphene oxide (PR-G) from natural and synthetic graphite as the material of an electrode for super condensers in Et4NBF4 1M in acetonitrile electrolyte ${ }^{31}$. The outcome of the results indicates the initial specific capacity of all samples was negligibly small around the latent or potential of the open circuit, which was in agreement with the small BET surface of the rGO powder of about $5 \mathrm{~m}^{2} / \mathrm{g}$. On the first cycle of potential, an electrochemical activation occurred at a specific capacity at $220 \mathrm{~F} / \mathrm{g}$ for the samples which have a graphene film/layer space of $0.44 \mathrm{~nm}$. So, it was found that the potential for the reaction of anodic and cathodic, the electrochemical activation is a purpose of the graphene oxide layer distance. The results reveal that both natural and the unreal or synthetic graphite are the good materials for the preparation of GO-based electrodes.

\section{Electrochemically Reduced Graphene Oxide}

GO is reduced electrochemically known as ER-G have been analyzed ${ }^{32}$. ER-G is characterized by the scanning electron microscope, transmission electron microscopy, XPS and X-ray diffraction. The results 
of ER-G presented an electrochemical capacitance and life-long cycle carbon nanotubes (CNT) and also chemically reduced graphene. The specific capacity measured by cyclic voltammetry $20 \mathrm{mV} / \mathrm{s}$ is about 165,86 and 100F/g for ER-G, CNT and chemically reduced graphenerespectively. The reduction of oxygen and hydrogen peroxide by electrochemical is significantly improved in ER-G electrodes compared to CNT. Therefore, ER-G shows the promising characteristics for uses in, biosensors, and energy storage and electro catalysis.

The electrochemical reduction of graphene oxide was carried out by a quick, efficient and friendly electrochemical method with the cyclic potential and environment, without using any reduction reagent ${ }^{33}$. ERGO were characterized by measurements of the UV-Vis, EIS and zeta potential. However, some electrochemically stable residues remain, which allows ERGO to facilitate the penetration of electrolytes and pseudocapacitance. Since ERGO easily stabilized by the bicycle the cathode potential, it exhibits exceptional stability in the life cycle. The results indicate that the specific capacity of $223.6 \mathrm{~F} / \mathrm{g}$ was achieved $5 \mathrm{mV} / \mathrm{s}$, which causes the ERGO is a competitive system for electrochemically drive storage material.

\section{Thermally Reduced Graphene Oxide}

In this work the effect of the temperature by reduction on graphene oxide was investigated ${ }^{34}$. After performing, at precise temperatures of 200,600 and $1000^{\circ} \mathrm{C}$, the changes of crystallographic and morphological were determined by different methods of analysis. The results indicate that the morphological and structural analyzes indicated a more structure of compact with a smaller superficial area and more defined graphitic structure. The rGO were used as super-condensing electrodes and examined with various electrochemical techniques. The results propose that the capacity exhibited increased to $600^{\circ} \mathrm{Cbefore}$ falling sharply to $1000^{\circ} \mathrm{C}$. This leads to the ionic layer of compact graphene limited accessibility.

Three types of rGO were prepared by reduction of hydrothermal at dissimilar conditions of $\mathrm{pH}$ and their pseudo-capacitive performance is evaluated using whole cell supercapacitor devices ${ }^{35}$. It was found that $\mathrm{pH}$ values have a major impact on the act of the supercapacitors, reaching the highest specific capacity value reported for the rGO hydrothermal supercapacitors. The result revealed that the graphene formed in the basic solution (graphene doped with nitrogen) has mainly a double layer behavior with a capacity of $185 \mathrm{~F} / \mathrm{g}$, while graphene produced under neutral or acid conditions shown both pseudo capacitive as behavior with specific capacity of $225 \mathrm{~F} / \mathrm{g}$ (acid) and $230 \mathrm{~F} / \mathrm{g}$ (neutral), respectively, at a constant current density of $1 \mathrm{~A} / \mathrm{g}$. Therefore, it indicates that HTrGO-B has mainly shown an EDLC performance with less specific capacity.

Graphene Oxide (GO) reduction is a capable low-cost synthetic method to majority graphene, which offers a nearby path to transparent conductive films and flexible electronics. Here, a strategy for real-time repair is presented from the thermal decomposition of an adequate precursor ${ }^{36}$. The conductivity of the monolayer graphene plate thus obtained has been increased more than six times to $350-410 \mathrm{~S} / \mathrm{cm}$ (which retains a transparency> 96\%). The result from XPS and Raman spectroscopy shows that the improvement in conductivity leads to the development of $\mathrm{sp}^{2}$-Carbon structures additionally. This technique provides a simple and effective process for extremely transparent and conductive graphene films.

Preparation of huge amount of graphene materials is based on oxidation of graphite oxide graphite and exfoliation of graphite oxide thermally to TR-GO ${ }^{37}$. Six graphite materials were characterized in the series of particle sizes and TR-GO material products prepared by using scanning electron microscopy, Raman spectroscopy and photoelectron spectroscopy result indicated the absence of correlation between the length of the unique graphite and the nature of the resultant material of TR-GO, such as the density surface defects, the amount of oxygen-containing groups or the heterogeneous electronic transfer rate (HET).A positive match between the HET speed and the high density of defects, as well as a low amount of oxygen functionality. The result reveals that there is an influence in the practical production of graphene for applications in sensors and energy storage devices.

\section{Synthesis of Reduced Graphene Oxide From Surfactants}

Graphene materials stabilized with graphene surfactant oxide intercalation with different surfactants, tetra-butyl ammonium hydroxide (TBAOH), cetyl-trimethylammonium bromide (CTAB) and dodecyl 
RASĀYAN J. Chem.

Vol. 12 | No. 1 |214 - 231| January - March | 201

benzene sodium sulfonate (SDB) followed by reduction was prepared with hydrazine ${ }^{38}$. The materials were characterized and found that the surfactants were successfully inserted into GO and rGO. The stability of morphology of the single layer or few layers of sheets of graphene during the reduction and the existence of surfactants in the materials of graphene can also increase on the wet nature of the superficial of graphene and thus recover its routine or performance as a superconducting electrode. The results show that when graphene is used as electrode materials for a supercapacitor, the high specific capacitance of $194 \mathrm{~F} / \mathrm{g}$ was obtained at the density of $1 \mathrm{~A} / \mathrm{g}$ in $2 \mathrm{M} \mathrm{H}_{2} \mathrm{SO}_{4}$ electrolyte.

Solid wood-based superconducting solid state using reduced graphene oxide (GRO) coated with a wooden cross-section (WTSS) as an electrode material for the first time with an economical, ecological and modest method ${ }^{39}$. The WTSS RGO coated electrode has a 3D porous honeycomb-shaped frame due to the substrate WTSS hierarchical cell structure and functionalize as an electrolyte reservoir. The results show that the electrode with good capacitance behavior and excellent cycle stability of $98.9 \%$ retention capacity after 5000 cycles. Supercapacitors show very noble mechanical flexibility and maintain constant capacitive behavior almost under different conditions. It also features an innovative and environmentally friendly design for electrodes in the future storage of flexible material energy devices that closely resemble natural materials.

Thiophene, chemistry reducing dual function agent were used to produce the reduced graphite oxide following the chemically reduced $\mathrm{GO}$ and the healing of $\mathrm{rGO}^{40}$. The resultant nanosheets of impurities did not contain nitrogen or sulfur, which was highly oxygenated and shows a healing effect (surface damage/cracks in the surface). Therefore, the electrical behavior of the rGOCT was prepared more to those of the conventional GRO produced with hydrazine requiring difficult reaction conditions. From the result, it is shown that the experimental work of XPS, XRD, TGA, TEM, Raman spectra and AFM reveal the high-quality GRO formation. The result reveals that the new double-reduction and healing method that uses thiophene saves energy and enable the marketable large production of high-quality graphene.

In this study, GO and irradiated graphene oxide was characterized respectively by X-ray diffraction, Raman spectroscopy and photoelectron spectroscopy by an electron beam with an absorbed dose, the structural effects were studied in graphene oxide $(\mathrm{GO})^{41}$. From the results, it indicates that the distance between the layers oxide of graphene decreases due to the percentage change in the functional group and the reduction effect. Even the graphics structure of GO was slightly disordered. Furthermore, the samples were partially reduced after irradiation and irradiation with GO electron beam performed to be a favorable process for the large-scale production of graphene.

\section{Graphene Sheets}

In recent years, especially carbon nanosheets (CNS) consist of tubular structure similar to the open-walled carbon nanotube ${ }^{42}$. Graphene nanosheets (GNS) have also attracted considerable attention because of their unique properties. These nanosheets are obtained by wrapping spiral graphene sheets systematically and high carrier mobility, mechanical strength, and thermal conductivity. Analysis samples were used to express the energy of the $(16,0)$ GNS band and the controlled Fermi energies were modeled in degenerate and non-degenerate energies. The model revealed that degenerated and non-degenerate approaches can be used for normalized Fermi energies above 3 and below -3, respectively.

Graphene plates with different levels of reduction were formed by thermally reduced of graphene oxide at the temperature of $200-900^{\circ} \mathrm{C}^{43}$. The effects of spacing between the layers, the oxygen content, the surface area and the degree of disorder in their specific capacity are systematically explored. From the results, it emerges that the difference of oxygen-containing groups has been indicated as an important factor which affects the act of the pyrolytic graphene EDL capacitor. A maximum capacity of $260.5 \mathrm{~F} / \mathrm{g}$ at a charge / discharge current density of $0.4 \mathrm{~A} / \mathrm{g}$ was obtained for the thermally reduced sample at about $200^{\circ} \mathrm{C}$.

The mechanism for expansion of graphite oxide thermally to produce functionalized sheets of graphene by the detailed analysis provided ${ }^{44}$. Exfoliation occurs when the rate of decomposition of the epoxide and hydroxyl groups of the graphite oxide which exceeds the rate of diffusion of the released gases, producing pressures exceeding the Vanderwaals forces holds the graphene sheets together. As a consequence of their rough nature, the defective and graphene sheet which was functionalized will not be reduced again into 
graphite oxide, but they are highly agglomerated. After ultrasonic dispersion in suitable solvents, statistical examination using AFM indicates that the $80 \%$ of the flakes observed.

For the manufacture of individual sheets of graphene functionalized through the exfoliation of graphite oxide thermally has been described ${ }^{45}$. The process produces a crumpled sheet structure from the reaction sites in the processes of oxidation and reduction. The topological characteristics of the individual sheets were measured by AFM, which indicates that the predictions correspond to the atomistic models of the first principles. It suggested that the growth of new materials such as electrically conductive polymers and ultracapacitors.

Graphene nanosheets (GNS) were prepared from graphite (artificial) by oxidation, fast expansion and ultrasonic treatment ${ }^{46}$. The structure and electrochemical performance GNS as anodic material for the lithium-ion systematically examined by high-resolution transmission electron microscopy, scanning electron microscopy, X-ray diffraction, infrared spectroscopy, Fourier transform spectroscopy and electrochemical test techniques. The result indicates that the GNS shows great reversible capacitance of $672 \mathrm{mAh} / \mathrm{g}$ and good-cycle performance. The current density exchanged with increased GNS with the progress of the number of cycles that show the peculiar electrochemical performances. A supercapacitor based on electromagnetic graphene chemistry showed specific capacitance as tabulated in Table-1.

Table-1: A supercapacitor based on electromagnetic graphene chemistry

\begin{tabular}{c|c|c}
\hline \multicolumn{3}{c}{ Chemistry of Graphene } \\
\hline Radiation & Neutral Electrolytes in F/g & Organic Electrolytes in F/g \\
\hline Electromagnetic & 99 & 135 \\
\hline Microwave & 190 & 120 \\
\hline
\end{tabular}

Two types of graphene sheets were functionalized by exfoliation (graphite oxide thermally) ${ }^{47}$. The first type of these graphene sheets was obtained by exfoliation of low-temperature graphite oxide in the air. The second type was prepared by carbonization of the first kind of graphene sheets functionalized at a higher temperature in $\mathrm{N}_{2}$. The result suggests that scanned electron micrograph images show that both types of samples have nanoporous structures. The results of the BET analysis indicate that both types of samples have high BET surface areas. The results of the electrochemical tests indicate that the specific capacitance of the functionalized graphene sheets of electrolyte $\mathrm{KOH}$ about $230 \mathrm{~F} / \mathrm{g}$ and the specific capacitance values of the second kind of (functionalized) graphene sheet have high surface area about 100 $\mathrm{F} / \mathrm{g}$, the result revealed that the second category has a higher retention capacity at a high current density because of its good conductive behavior.

A high-quality graphene plate was formed from graphite powder by oxidation which was by fast thermal development in a nitrogen atmosphere ${ }^{48}$. The process was studied by X-ray diffraction (XRD), infrared spectroscopy, Fourier transform (FTIR), and Raman Brunauer-Emmett-Teller (BET) spectroscopy. The morphology examination of graphene sheets was characterized by scanning electron microscopy (SEM) and high-resolution transmission electron microscopy (HRTEM). The electrochemical study was performed in coin-type cells compared to lithium. The results indicate that the graphene sheets have a surface area consisting of a wrinkled thin structure, fewer layers of layers and high surface area of 492.5 $\mathrm{m}^{2} / \mathrm{g}$. The reversible specific capacitance of the graphene sheets was $1264 \mathrm{mAh} / \mathrm{g}$. Even with a huge current density of $500 \mathrm{~mA} / \mathrm{g}$, the reversible specific capacitance was sustained at $718 \mathrm{mAh} / \mathrm{g}$. After 40 cycles, the reversible capacitance was performed at $848 \mathrm{mAh} / \mathrm{g}$ at $100 \mathrm{~mA} / \mathrm{g}$. These results show that the extraordinary quality graphene sheets prepared have excellent electrochemical development for lithium storage.

The reduction of the colloidal suspension of the exfoliated sheet of GO in water with hydrate hydrazine leads to the accumulation and subsequent formation of a carbonaceous material with high surface area, which has a sheet on the base of their thin graphene ${ }^{49}$. The reduced material is determined by elemental analysis, heated gravimetric analysis, electron microscopy, NMR spectroscopy, Raman spectroscopy and measurement of current. The results of the characterization show that the reduced graphene oxide specifies the treatment of hydrazine leads to the production of conjugated and unsaturated carbon atoms, which confer electrical conductivity. The result shows that the reduction of the GO sheets expanded with 
hydrazine in water, results in characteristics of the graphite material that are analogous to those of the uncontaminated graphite.

The step-by-step controllable reduction of individual graphene oxide sheets thermally, combined into multi-terminal field effects devices was performed at low temperatures of $125-240^{\circ} \mathrm{C}$ with electrical measurements ${ }^{50}$. The result reveals that the symmetric electron- and hole-type dependences were observed. The conductivity of each fabricated systems depends on the reduction level that enlarged more than 106 times as the reduction progressed, the power of the external electric field, the density of the current and the temperature was observed.

Supercapacitors, conserving the electrical charge in high surface conductive materials. Chemical activation using expanded graphite oxide has been synthesized porous carbon having a surface area up to 3100 square meters/gram, shows low oxygen, large electrical conductivity and hydrogen content ${ }^{51}$. This $\mathrm{sp}^{2}$-bond of carbon consists of continuous 3D-network of many curved walls, with only one atom and formed mainly with nano-wide pores. The super condensed cells with two electrodes built with this carbon have produced high values of gravimetric capacity and energy density with liquid organic and ionic electrolytes and this carbon is easily scalable at the industrial level. Using this type of simple activation process has already been commercially proven AC, can be done for a-MEGO and a-TEGO production scale production for advanced energy storage systems/devices in a short period.

Catalytic activation of carbon materials recently used to prepare porous graphene-like (PG) materials with a large surface area and outstanding electrical conductivity for supercapacitor applications ${ }^{52}$. The influence of morphologies and carbonaceous precursor structures on the structure and on the electrochemical assets of PG products has been studied. The result shows that using hollow microspheres with carbonaceous precursor thin walls, is obtained with PG large specific area, pore structure and high abundant graphitization degree exhibits the large specific capacitance and outstanding cyclic stability. This approach not only provides a real way to synthesize high porous graphene materials for supercapacitor applications but also shows great potential in other applications, such as catalysis and gas adsorption.

Compounds of highly dispersed Si nanoparticles between graphene sheets and maintained by a 3D complex formed by reconstituting graphite stacks region shows superior memory capacities of Li-ion and cyclic stability ${ }^{53}$. The result shows that the electrode was prepared with a storage capacity of $42200 \mathrm{~mA} \mathrm{~h}$ /g after 50 cycles and $41500 \mathrm{~mA} \mathrm{~h} / \mathrm{g}$ after 200 cycles which decreased by $0.5 \%$ per cycle. The results also show that Si nanoparticles are well dispersed in the graphene compound, and a part of graphene sheets reconstitutes the graphite to form a highly conductive 3-D continuous network also functions as a structural scaffold to anchor graphene plates that will hit and will trap the Si nanoparticles.

\section{GO Hydrogels}

The easy and scalable method for the formation of hydrogels reduced GO through the electro deposition of GO and its high-performance super-condensing electrode. ${ }^{54}$ The results indicate that the systems exhibited a specific capacitance of 147 and $223 \mathrm{~F} / \mathrm{g}$ at a density of $10 \mathrm{~A} / \mathrm{g}$ using $\mathrm{H}_{2} \mathrm{SO}_{4}$ and hydroquinone as redox electrolytes. ERGO has exhibited excellent specific capacity, speed performance, and cycling stability. The results demonstrated the great potential of hydrogel ERGO as a favorable electrode material for high-performance supercapacitors.

A new and controllable way for producing a robust and high performance of 3D graphene structures has been carried out by a crosslinking reaction is between GO and EDA causing a large area of the highly conductive surface and a graphene hydrogel solid 3D network oxide. ${ }^{55}$ The reduced hydrogel of graphene oxide is produced by a cross-binding reaction with ethylenediamine followed by hydrazine reduction. From the results, it indicates that the material shows a large conductivity of $1351 \mathrm{~S} / \mathrm{m}$ and a surface of $745 \mathrm{~m}^{2} / \mathrm{g}$. When it is used as an electrode, it shows a high specific capacitance of $232 \mathrm{~F} / \mathrm{g}$.

\section{GO Films}

The conductivity of the GO films using reducing agents is modified ${ }^{56}$. The effect of reducing agents on the film strength of GO films has been described. It was found that the conflict of the reduced graphite oxide film layer using sodium borohydride is lesser than the films reduced with hydrazine $\left(\mathrm{N}_{2} \mathrm{H}_{4}\right)$. The 
results indicate that there is a formation of $\mathrm{C}-\mathrm{N}$ groups in the case of $\mathrm{N}_{2} \mathrm{H}_{4}$ which may act as donors compensating the whole carriers in reduced graphite oxide. Generally, the reduction of $\mathrm{NaBH}_{4}$, the distance of the intermediate layer is slightly expanded before forming in-between boron-oxide complexes and then constricted by gradual hydroxyl and carbonyl groups together with the boron-oxide complexes. Comparable to that of dispersed graphene, the fabricated conducting film comprising a $\mathrm{NaBH}_{4}$-reduced graphite oxide reveals a sheet-like resistance structure.

A standard DVD Light Scribe optical drive was used to perform the direct laser reduction of oxide films on graphene ${ }^{57}$. The produced film is mechanically robust, showing large electrical conductance of 1738 Siemens/ meter and an area of 1520 square meters/gram and used directly as electrodes without the current collectors or binders, as in the event of ECs conventional. The results revealed that procedures made with these types of density electrodes exhibit very high energy ethics in dissimilar electrolytes while upholding a great power density and outstanding EC cycle stability. Furthermore, these ECs maintain brilliant electrochemical properties under high powered pressure and therefore promise a high power flexible electronics.

\section{Composites of Graphene}

\section{Graphene/Polymer Composites}

A pigment-cellulose nanofibrils ( $\mathrm{PCN}$ ) compound has been used as a separation substrate in graphene and CNT printed super capacitors ${ }^{58}$. Compounds typically consisted of $80 \%$ and $20 \%$ of pigment and cellulose nanofibrile (CNF) respectively. The assets of these substrates from the selection of raw materials and their relative proportions can be varied. A semi-manufacturing scale trial line has been fruitfully used to produce flat, flexible and nanoporous composite materials and their performance has been evaluated on a dual-function separator-substrate element in the supercapacitors. The result shows that the nano-structure carbon films on the composite functions simultaneously as high active surface conductors and existing collectors.

The graphene oxide / polyaniline compound (GO / PANI) was equipped by the electrochemical co-deposition-method $^{59}$. The different GO mass concentrations were used to improve electrochemical performance. The morphology studies of the SEM and TEM images represents the nanofibers were not only coated on the apparent but also interspersed with GO sheets. From the results it follows that the maximum of the GO-specific PANI-specific capacity reached $1136.4 \mathrm{~F} / \mathrm{g}$ with a graphene oxide concentration of $10 \mathrm{mg} / \mathrm{L}$ at a scanning speed of $1 \mathrm{mV} / \mathrm{s}$, which is almost twice the greater of PANI 484.5 F/g. The GO / PANI compound also showed good cyclic strength, the initial capacitance retained 89\% after 1000 cycles. One result indicates that GO/PANI compounds can develop the excellent high performance of electrode materials with a versatile, efficient and environmentally friendly method.

The conducting polymers poly-3, 4-ethylene dioxythiophene (PEDOT), polyaniline (PANi), and polypyrrole (PPy) ${ }^{60}$ were coated directly on the superficial of the reduced oxide graphene sheets (RGO) by an in-situ polymerization process for preparing RGO-polymer nanocomposites with different fillers of conducting polymers. The result indicates that the ethanol shows a significant part in attaining an even polymeric coating on GRO sheets. The electrochemical assets of the composite materials have been considered using voltammetry and loading / unloading techniques. From the results, it indicates that the compound consisting of GRO and PANI (GRO-pani) has a capacitance of $361 \mathrm{~F} / \mathrm{g}$ at a density of $0.3 \mathrm{~A}$ /g. The compounds of PPy and GRO (GRO-PPy) and PEDOT (GRO-PEDOT) showed specific capacities 248 and $108 \mathrm{~F} / \mathrm{g}$ respectively at current density. A good capacitive performance polymeric conductive composites GRO is credited to the contributions of both the EDLpseudocapacitance capability with the good electrical conductivity of the composites.

The production, application and characterization of graphene $(\mathrm{G})$ and polyethylene dioxythiophene (PEDOT) nanocomposites used as an electrode material for applications of supercapacitors ${ }^{61}$ have been studied. The G-PEDOT nanocomposite was formed by the technique of chemical oxidative polymerization. It was characterized by scanning electron microscopy (SEM), transmission electron microscopy (TEM), Raman spectroscopy, FTIR spectroscopy, X-ray diffraction, electrochemical impedance spectroscopy (EIS) and cyclic voltammetry (CV) techniques. The result illustrates the nanocomposite electrochemical characteristics in dissimilar electrolytic condition and the capacitance of 
discharge has been estimated at $374 \mathrm{~F} / \mathrm{g}$. This work demonstrated capacitance of electrode studies in the G-PEDOT with respect to material stability, specific capacity, electrical conductivity and specific charge / discharge properties of electrodes.

A new graphene-polyaniline nanocomposite material synthesized with the technique of chemical precipitation is described as a material of an electrode for supercapacitors ${ }^{62}$. Graphene $(G)$ and polyaniline (PANI) nanocomposite film was mixed in NMP and characterized by Raman spectroscopy, FTIR, scanning electron microscopy, transmission electron microscopy and CV techniques. The structure of the composite was detected using different proportions of a monomer of graphene and aniline. It is produced using G-PANI in N-methyl-2-pyrrolidone (NMP) and G-PANI- films in graphite electrodes. A capacitance of $300-500 \mathrm{~F} / \mathrm{g}$ at $0.1 \mathrm{~A} / \mathrm{g}$ is observed on the graphene-PANI nanocomposite materials.

Nanocomposites to develop high-performance graphene, control of the interface and the graphene was dispersed in the polymer is a challenge for its strong cohesive energy and surface inertia. To functionalize the GO with 4-aminophenoxyphthalonitrile with poly-arylene ether nitrile to prepare the nanocomposite films ${ }^{63}$. The characterization studies of FTIR, Raman spectrum and the atomic force microscope (AFM)to examine the functionalization of the graphene oxide surface. The resulting nanocomposite-PEN with $0.75 \%$ by weight of functionalized nitrile, revealed a $27 \%$ increase and $68 \%$ in tensile power and Young's modulus respectively. According to the authors, the mechanical and thermal properties of the PEN composite films have been further improved by chemical reaction of crosslinking of nitriles, which lead to the optimization of the structure at the interface and recover the full performance of graphene-polymer nanocomposites.

A simple path to synthesize nanocomposites on graphene and polypyrrole nanofibers using a biopolymer such as sodium alginate has been explored ${ }^{64}$. The composite synthesis process is simple, economic and ecological. The interface between nanofibers of graphene and PPy were characterized by FTIR analysis. From the morphological studies, PPy as fiber in the nanocomposite morphology of graphene was established. A large electrical conductivity of $1.45 \mathrm{~S} / \mathrm{cm}$ at room temperature was noticed and also showed non-linear current/voltage characteristics, which indicates that it can be used in different applications of the device. The result suggests that capacity value of $466 \mathrm{~F} / \mathrm{g}$ maximum was obtained.

Nano materials with almost 0,1 , and 2 dimensionalities with silicon nanoparticles, CNT, $\mathrm{TiO}_{2}$ particles and graphene flakes, are incorporated into the conductive polymer of polyaniline to form materials of nanocomposite for the fabrication of flexible supercapacitor sheets ${ }^{65}$. The results reveal that the polyaniline nanomaterial significantly improved the energy and power capabilities of the capacitor with the specific capacitance of $477 \mathrm{~F} / \mathrm{g}$ were obtained. The properties of CNT have also been studied to improve the storage of the charge and reduce the conflict of the nanocomposite material. The results indicate that the capacitor of the nanosheets was used to power the LED to prove the potential of the nanocomposite based condenser sheet in lighting applications.

The nanosheets-poly (o-aminophenol) nanocomposite (POAP / GNS) was made up on a surface of platinum by a potential cycle ${ }^{66}$. The results of the POAP / GNS / Pt. electrode voltages showed outstanding capacitive behavior by a redox transition with an average peak potential of $295 \mathrm{mV}$. The POAP /GNS nanocomposite shows a specific capacitance of $281.1 \mathrm{~F} / \mathrm{g}$ at $0.1 \mathrm{~A} / \mathrm{g}$, which is almost three times that of pure graphene. From the results, it specifies that the power and energy of the material of nanocomposites $25 \mathrm{Whk} / \mathrm{g}$ and $34.8 \mathrm{Wk} / \mathrm{g}$, respectively. The nanocomposite retained the initial capacity of $99 \%$ after 1200 charge/discharge cycles and synthesized nanocomposite showed high specific capacity with excellent cycle stability.

A graphene-based comparative study and PANI nanocomposite derivatives, i.e. 'methoxy', aniline 'methyl' with graphene for supercapacitors applications. G-polyaniline, poly (o-methoxy aniline) [poly (oanisidine) (POA)] and G-poly (O-methyl aniline) [poly (o-toluidine)] were synthesized by a method of chemical oxidative polymerization and characterized by the development of nanocomposite materials ${ }^{67}$. The electrochemical nature of the G-PANI, G-POA and G-POT based superconducting nanocomposites was examined by cyclic voltammetry, galvanostatic, and electrochemical impedance techniques. The result shows that specific capacities built on G-PANI, G-POA and G-POT at $2 \mathrm{M} \mathrm{H}_{2} \mathrm{SO}_{4}$ electrolyte at 400, 380 and $425 \mathrm{~F} / \mathrm{g}$, respectively. However, the nanocomposite POA with graphene showed a better capacity of $425 \mathrm{~F} / \mathrm{g}$ compared to G-polyaniline and it was calculated from the EIS 
analysis and these time constants shows a faster delivery of energy stored in carbon-carbon-based supercapacitors.

The polyaniline sandwich / grapheneNano sheet was produced by the technique of chemical oxidation polymerization of the aniline monomer onto the reduced surfaces of GO nanosheets with the absence of surfactants. The influence of aniline mass ratio reduced the size of $\mathrm{GO}$ and nanocomposite polyaniline / graphene morphologies were investigated ${ }^{68}$. As the weight ratio of aniline oxide and reduced graphene is less than 12:1, the polymerization reaction of the aniline produced in the reaction of reduced heterogeneous nucleation to form polyaniline compounds / graphene oxide sandwich surfaces. However, in addition to polyaniline / graphene -sandwich nanowires, polyaniline nanofibers are formed by homogeneous nucleation. In comparison with reduced graphene oxide and polyaniline nanofibers, the results indicate that the similar graphite polyaniline/ graphene sandwich nanosheets obtained show good electrochemical performance due to the effect between polyaniline and graphene.

Synthesis of nanocomposite polypyrrole / molybdenum disulfide (PPy / $\mathrm{MoS}_{2}$ ) as a material of an electrode for advanced high-performance supercapacitor applications has been carried out ${ }^{69}$. The flowerlike $\mathrm{MoS}_{2}$ with graphene-like subunits structure is prepared using a hydrothermal method and the nanocomposite PPy are embedded in $\mathrm{MoS}_{2}$ nanosheets is prepared by in situ oxidation polymerization of pyrrole in the presence of $\mathrm{MoS}_{2}$ suspension The characterization of the nanocomposites were investigated by the measurements of XRD, FE-SEM and TEM. Its electrochemical studies are also performed by cyclic voltammetry and charge/discharge studies. The results reveal that the PPY / $\mathrm{MoS}_{2}$ nanocomposite has a large specific capacity of $553.7 \mathrm{~F} / \mathrm{g}$ and the capacitance remains at $90 \%$ at $1 \mathrm{~A} / \mathrm{g}$ after 500 cycles. This new nanocomposite has significant potential to be further exploited in superconducting devices.
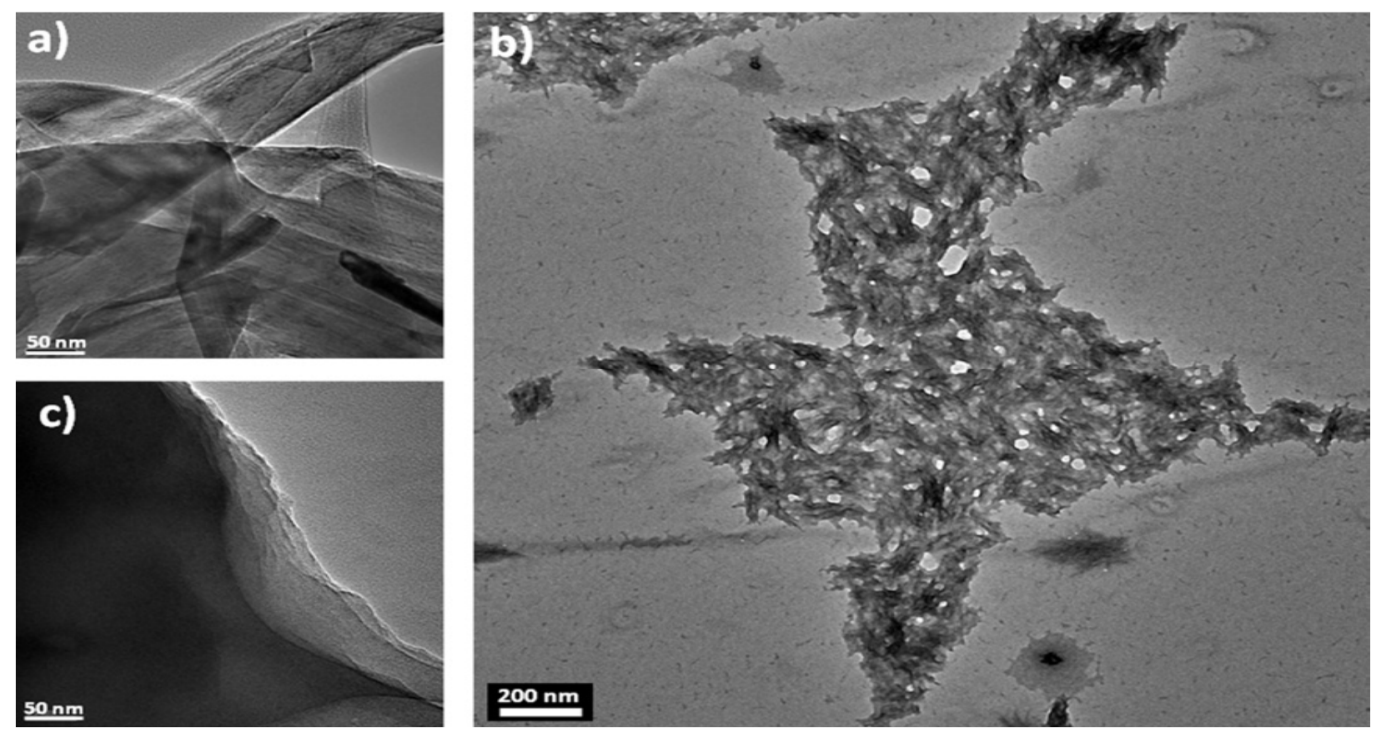

Fig.-1: TEM Picture of the Graphene Platelets used for the Synthesis (a), the G-PANI Nanocomposite Film Structure (b), and Their Resulting Interaction in the Polymer Nanocomposite Network ${ }^{62}$ (c)

\section{Graphene/Metal Oxides}

Nanocomposite reduced graphene $\mathrm{Co}_{3} \mathrm{O}_{4}$ oxide (GRO) are co-precipitation of $\mathrm{Co}(\mathrm{OH})_{2}$ with GO to form a $\mathrm{Co}(\mathrm{OH})_{2}-\mathrm{GO}$ precursor, by heat treatment ${ }^{70}$. The relationship between $\mathrm{Co}_{3} \mathrm{O}_{4}$ and $\mathrm{rGO}$ has an important role of effect on its electrochemical activities. A capacitance of $636 \mathrm{~F} / \mathrm{g}$ is observed .A new asymmetric supercapacitor with $\mathrm{Co}_{3} \mathrm{O}_{4}-\mathrm{RGO}$ nanocomposite as an anode and activated carbon as a cathode in aqueous electrolyte $6 \mathrm{M} \mathrm{KOH}$ is produced. The result indicates that the complex would be an asymmetrical reverse cycle and voltage from 0 to $1.5 \mathrm{~V}$ and exhibited a high energy density of 35.7 Whk/g at a power density of $225 \mathrm{~W} \mathrm{k} / \mathrm{g}$. In addition, the asymmetric supercapacitor shows outstanding cyclic stability with a $95 \%$ storage capacity after 1000 cycles at $0.625 \mathrm{~A} / \mathrm{g}$. 
$\mathrm{SnO}_{2}$-reduced graphene oxide nanocomposite in the form of a free-standing film was prepared by chemical synthesis ${ }^{71}$. The homogeneous and compact formation of the nanocomposite of $\mathrm{SnO}_{2}$ and the reduced graphene oxide was confirmed by several methods of analysis. The result reveals that when combined with the anode in lithium-ion batteries, it shows high capacitance of $503 \mathrm{~m} \mathrm{Ah} / \mathrm{g}$ was observed and very stable cycle time. The result exhibited a much-improved cycle performance, which leads to the film's strong and homogeneous composite structure.

Molybdenum dioxide nanoparticles with $100 \mathrm{~nm}$ of diameter were attached equally to 3Dgraphene foam by using an ultrasonically assisted deposition method ${ }^{72}$. The XRD and Raman spectroscopy shows that the nanoparticles of molybdenum dioxide have a monoclinic crystalline structure. The compound 3D graphene / nanoparticles $\mathrm{MoO}_{2}$ showed excellent pseudo capacitive capacity from its specific capacity reached 404F/gin the neutral solution. The graphene / $\mathrm{MoO}_{2}-3 \mathrm{D}$ nanoparticle composite has great potential as an anodic measurable for the next group of high-performance supercapacitors

$\mathrm{Bi}_{2} \mathrm{O}_{3} / \mathrm{RGO}$ composite rods were formed by precipitation method and calcination method ${ }^{73}$. The crystallinity, morphological studies were characterized by X-ray diffraction (XRD), field emission scanning field microscopy (FE-SEM) and of high-resolution transmission electron microscopy (HRTEM). The behavior of the supercapacitor was performed by using cyclic voltammetry, galvanostatic charge /discharge and impedance analysis. The result indicates that the $\mathrm{RGO}-\mathrm{Bi}_{2} \mathrm{O}_{3} /$ nanocomposite bars have a specific maximum capacity of $1041 \mathrm{~F} / \mathrm{g}$ at $2 \mathrm{~A} / \mathrm{g}$. The activity of photocatalysis of $\mathrm{Bi}_{2} \mathrm{O}_{3}$ rods/RGO composite was measured by photocatalytic degradation of methylene blue (MB) dye under UV-Visible irradiation. It is attributed to the synergistic effect between the bars of $\mathrm{Bi}_{2} \mathrm{O}_{3}$ and graphene sheets which effectively prevents the recombination of electron pairs of photogenerated holes and in $\mathrm{Bi}_{2} \mathrm{O}_{3}$ bars. It provides a new approach to improve the performance of $\mathrm{Bi}_{2} \mathrm{O}_{3} / \mathrm{RGO}$ composite bars in energy storage systems and in environmental applications.

Graphene oxide was synthesized using the Modified Hummer's method and the graphene-NiO nanocomposite prepared according to the hydrothermal method with $\mathrm{GO}$ solution, $\mathrm{Ni}\left(\mathrm{NO}_{3}\right)_{2} \bullet 6 \mathrm{H}_{2} \mathrm{O}$ and urea as raw material ${ }^{74}$. The synthesized nanocomposite was characterized by techniques of, Raman spectroscopy, SEM, TGA and XRD by the dispersive energy spectrometer analysis. The results indicate that the $\mathrm{NiO}$ nanoparticles equally covered on the layer of the graphene layer and Raman studies indicate that the formation of the Nano-NiO-graphene composite wells. TGA analysis is used to analyze the quantity of graphene existing in the Graphene-NiOnanocomposite. The curves of the graphene-NiO electrodes with different scanning transmit the characteristic capacity is altered from the EDLC in which the shape is generally a perfect rectangular shape. From the results, it shows that the cyclic analysis of voltammetry is evidence that these materials have the property capacity of the superconducting electrode material.

The nano-based graphene compounds emerging a new group of materials that are promising for many applications. An easy approach to the formation of graphene / nanocomposites using GO and nickel chloride as reactants ${ }^{75}$. The synthesized material compounds were characterized by X-ray diffraction, infrared spectroscopy, Fourier transforms, transmission electron microscopy, UV-visible spectroscopy, thermo gravimetric analysis and differential scanning calorimetry. From the results, it was shown that graphene sheets were decorated by the in situ-formed $\mathrm{NiO}$ nanoparticles to form a film-like composite structure and as a result, the restacking of the as-reduced graphene sheets was effectively prevented. The $\mathrm{NiO}-$ coated graphenenanocompositescan be expected to improve the electrochemical properties of $\mathrm{NiO}$ and would be the promising candidates for a variety of applications in future nanotechnology.

The copper oxide nanoparticles $(\mathrm{CuO})$ were synthesized by ultrasonically assisted precipitation through heat treatment ${ }^{76}$. As the prepared $\mathrm{CuO}$ nanoparticles were attached on the layer of the graphene oxide (GO) by a simple electrostatic co-precipitation. It was characterized by FTIR, Raman spectroscopy, X-ray diffraction (XRD), X-ray photoelectron (XPS) and X-ray analysis of energy dispersive (EDX), FESEM and HRTEM and also the electrochemical methods including cyclic voltammetry, impedance spectroscopy, and charge/discharge cycles. The result shows that the material of the composite shows good electrochemical behavior and charge transfer resistance very low. It also shows better specific capacitance $245 \mathrm{~F} / \mathrm{g}$ at of $0.1 \mathrm{~A} / \mathrm{g}$ and in different current densities for 1000 cycles. From the results, it 
reveals that the composite is an outstanding applicant for energy storage systems in terms of cycle-ability and rate capability.

Graphene nanosheets (GNs) dispersed with $\mathrm{SnO}_{2}$ nanoparticles loaded multi-walled carbon nanotubes $\left(\mathrm{SnO}_{2}-\mathrm{MWCNTs}\right)$ were investigated as electrode materials for supercapacitors ${ }^{77}$. $\mathrm{SnO}_{2}-\mathrm{MWCNTs}$ were obtained by a chemical method followed by calcination. GNs $/ \mathrm{SnO}_{2}-\mathrm{MWCNTs}$ nanocomposites were prepared by ultrasonication of the GNs and $\mathrm{SnO}_{2}-\mathrm{MWCNTs}$. Electrochemical double layer capacitors were fabricated using the composite as the electrode material and aqueous $\mathrm{KOH}$ as the electrolyte. Electrochemical performances of the composite electrodes were compared to that of pure GNs electrodes and the result was discussed. From the results it shows that the electrochemical measurements show that the maximum specific capacitance, power density and energy density obtained for supercapacitor using $\mathrm{GNs} / \mathrm{SnO}_{2}-\mathrm{MWCNTs}$ nanocomposite electrodes has $224 \mathrm{~F} / \mathrm{g}, 17.6 \mathrm{~kW} \mathrm{k} / \mathrm{g}$ and $31 \mathrm{Wh} \mathrm{k} / \mathrm{g}$ respectively. The fabricated supercapacitor device exhibited excellent cycle life with $\sim 81 \%$ of the initial specific capacitance retained after 6000 cycles. The results suggested that the hybrid composite is a promising supercapacitor electrode material.

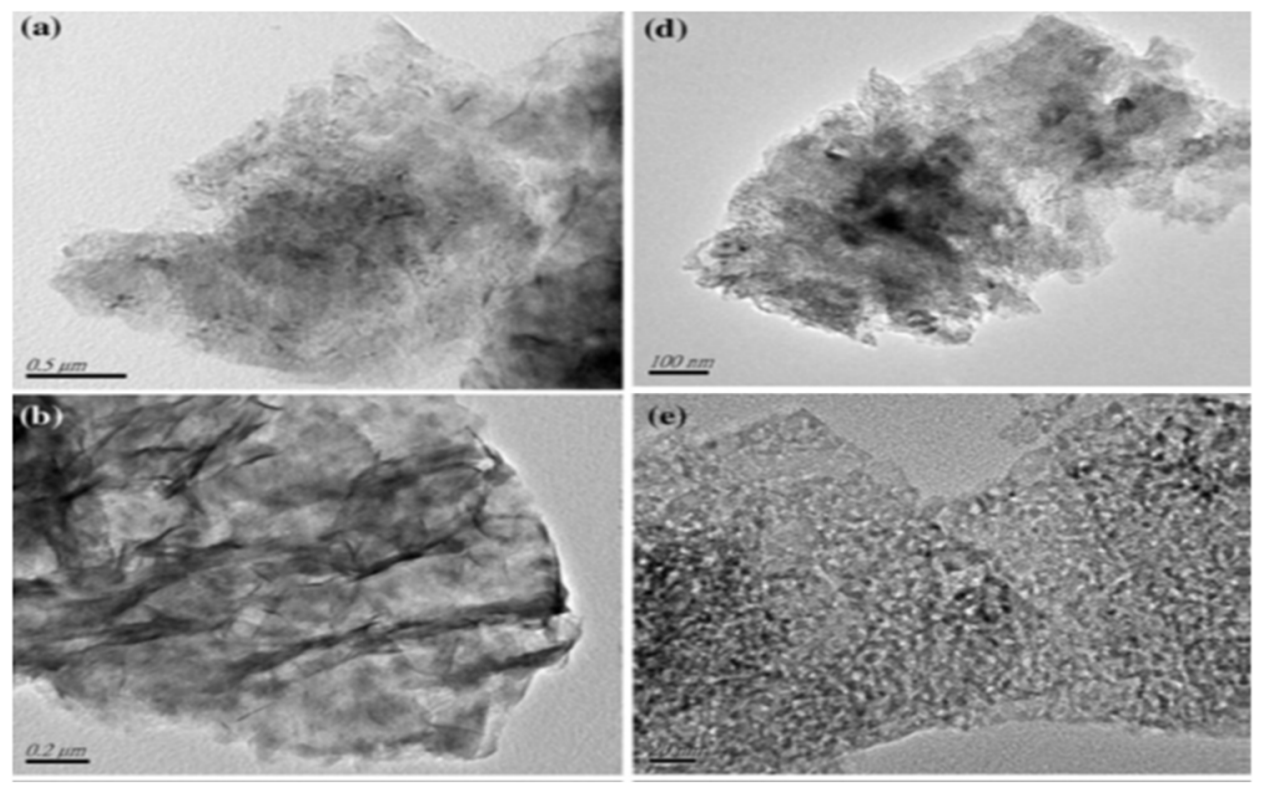

Fig.-2: (a) and (b) TEM Patterns of the Graphene/Ni(OH) $)_{2}$ Nanocomposites; (d) and (e) TEM Patterns of the Graphene/NiO Nanocomposites ${ }^{76}$

\section{Trends and Future Tasks}

Graphene has become one of the essential components in the fabrication of flexible electrodes because of its exceptionally high mechanical strength, excellent surface area, and good conductivity, which add extra advantages in preventing the electrode framework from being ruptured as a result of the mechanical bending/twisting of the flexible device. The significance and uniqueness of graphene in the fabrication of flexible components, indirectly generating a new research goal involving the fabrication of ultimate performance flexible energy-storage devices.

Many efforts were accomplished to improve the electrode materials including the combination of Electric Double Layer (EDL) capacitance with active materials of reversible pseudo capacitance, utilizing organic electrolyte or ionic liquids to achieve higher stability potential window or employing the hybrid asymmetric system to optimize the overall working potential. Polymeric gel electrolyte was often employed in deriving a high flexibility device, complimenting to the ability of gel structure to penetrate efficiently to the porous electrode, while providing a stable structure in maintaining the dimension that is not susceptible to the physical bending force.

Supercapacitor devices have heavily focused on the mechanical flexibility of solid-state devices, with the goal of maintaining their high electrochemical performance while following the significant trend of 
RASĀYAN J. Chem.

Vol. 12 | No. 1 |214 - 231| January - March | 201

portable and wearable electronics becoming small, thin, and flexible, which brings new challenges for energy-storage systems ${ }^{79}$.Despite all the results and excellent progress, one of the main obstacles in supercapacitor technology is the maximum production cost compared to other energy storage device. Therefore, future tasks should focus on the development of high-capacity graphene materials performance on an economically advantageous route. Synthesis of the one-step process without any additional treatment would be conducive to practicality on an industrial scale.

Table-2: The Capacitance, Current Density, the Surface Area of Porous Carbon Derived from Various Graphene/Nanocomposites Precursors

\begin{tabular}{|c|c|c|c|c|c|c|}
\hline S. No. & Precursor & ${ }^{\mathrm{a}} \mathrm{m}^{2} \mathrm{~g}^{-1}$ & ${ }^{\mathrm{b}} \mathrm{F} / \mathrm{g}$ & ${ }^{\mathrm{c}} \mathrm{A} / \mathrm{g}$ & Electrolyte & Reference \\
\hline 1 & GO/ Polyaniline composite & - & 1136.4 & 1 & $1 \mathrm{MH}_{2} \mathrm{SO}_{4}$ & 59 \\
\hline 2 & RGO/PANI composite & - & 361 & 0.3 & - & 60 \\
\hline 3 & RGO/ PEDOT composite & - & 108 & 0.3 & - & 60 \\
\hline 4 & RGO/ PDY composite & - & 248 & 0.3 & - & 60 \\
\hline 5 & $\begin{array}{c}\text { Nitrogen doped graphene } \\
{[\text { HTrGo-N] }}\end{array}$ & - & 185 & 1 & $\mathrm{KOH}$ & 35 \\
\hline 6 & HTrGo- A & - & 225 & 1 & $\mathrm{KOH}$ & 35 \\
\hline 7 & HTrGo- B & - & 230 & 1 & $\mathrm{KOH}$ & 35 \\
\hline 8 & 3D - graphene hydrogen & 745 & 232 & 1 & $2 \mathrm{M} \mathrm{KOH}$ & 55 \\
\hline 9 & $\mathrm{CO}_{3} \mathrm{O}_{4}-\mathrm{rGO}$ Nano composite & - & 636 & 0.625 & $6 \mathrm{M} \mathrm{KOH}$ & 70 \\
\hline 10 & ERGO & - & 223.6 & 0.5 & $1 \mathrm{M} \mathrm{H}_{2} \mathrm{SO}_{4}$ & 33 \\
\hline 11 & TBAOH & - & 194 & 1 & $2 \mathrm{M} \mathrm{H}_{2} \mathrm{SO}_{4}$ & 38 \\
\hline 12 & 3D Graphene / $\mathrm{MoO}_{2}$ & - & 404 & - & $1 \mathrm{M} \mathrm{Na}_{2} \mathrm{SO}_{4}$ & 72 \\
\hline 13 & GNS -200 & 71.50 & 260.5 & 0.4 & $6 \mathrm{M} \mathrm{KOH}$ & 43 \\
\hline 14 & GNS -200 & 71.50 & 200.6 & 4 & $6 \mathrm{M} \mathrm{KOH}$ & 43 \\
\hline 15 & $\mathrm{Bi}_{2} \mathrm{O}_{3}$ rods/ $\mathrm{RGO}$ & - & 1041 & 2 & $6 \mathrm{M} \mathrm{KOH}$ & 73 \\
\hline 16 & FunctionalizedGraphene sheets & 737 & 230 & - & $\mathrm{KOH}$ & 47 \\
\hline 17 & High Quality Graphene sheets & 492.5 & - & - & - & 48 \\
\hline 18 & Partially reduced GO & 5 & 220 & - & $\begin{array}{l}1 \mathrm{M} \mathrm{Et}_{4} \mathrm{NBF}_{4} \mathrm{in} \\
\text { acetonitrile }\end{array}$ & 31 \\
\hline 19 & RGO hydrogels & - & 147 & 10 & $\mathrm{H}_{2} \mathrm{SO}_{4}$ & 54 \\
\hline 20 & RGO hydrogels & - & 223 & 10 & $\begin{array}{c}\mathrm{H}_{2} \mathrm{SO}_{4}+ \\
\text { hydroquinone }\end{array}$ & 54 \\
\hline 21 & G - PEDOT & - & 304 & $\begin{array}{l}10- \\
15\end{array}$ & (redox) $2 \mathrm{M} \mathrm{KCL}$ & 61 \\
\hline 22 & $\begin{array}{c}\text { Graphene - PANI Nano } \\
\text { composite }\end{array}$ & - & $\begin{array}{l}300- \\
500\end{array}$ & 0.1 & $2 \mathrm{M} \mathrm{H}_{2} \mathrm{SO}_{4}$ & 62 \\
\hline 23 & GrPPyN & - & 466 & 1 & 1M KCL & 64 \\
\hline 24 & $\mathrm{CuO}_{2}$ on $\mathrm{GO}$ nanosheets & - & 245 & 0.1 & $1 \mathrm{M} \mathrm{Na}_{2} \mathrm{SO}_{4}$ & 77 \\
\hline 25 & POAP/ GNS & - & 281.1 & 0.1 & $1 \mathrm{M} \mathrm{H}_{2} \mathrm{SO}_{4}$ & 66 \\
\hline 26 & G - PANI & - & 400 & 1 & $2 \mathrm{M} \mathrm{H}_{2} \mathrm{SO}_{4}$ & 67 \\
\hline 27 & $\mathrm{G}-\mathrm{POA}$ & - & 380 & 1 & $2 \mathrm{M} \mathrm{H}_{2} \mathrm{SO}_{4}$ & 67 \\
\hline 28 & $\mathrm{G}-\mathrm{POT}$ & - & 425 & 1 & $2 \mathrm{M} \mathrm{H}_{2} \mathrm{SO}_{4}$ & 67 \\
\hline 29 & $\begin{array}{c}\mathrm{GNS} / \mathrm{SnO}_{2} \mathrm{MWCNTS} \\
\text { nanocomposite }\end{array}$ & - & 224 & 5 & $\mathrm{KOH}$ & 77 \\
\hline 30 & Ppy/ $\mathrm{MoS}_{2}$ Nano composite & - & 553.7 & 1 & 1M KCL & 69 \\
\hline
\end{tabular}

a-BET surface area $\quad b$ - Specific capacity $\quad c$ - Current density 
RASĀYAN J. Chem.

Vol. 12 | No. 1 |214 - 231| January - March | 201

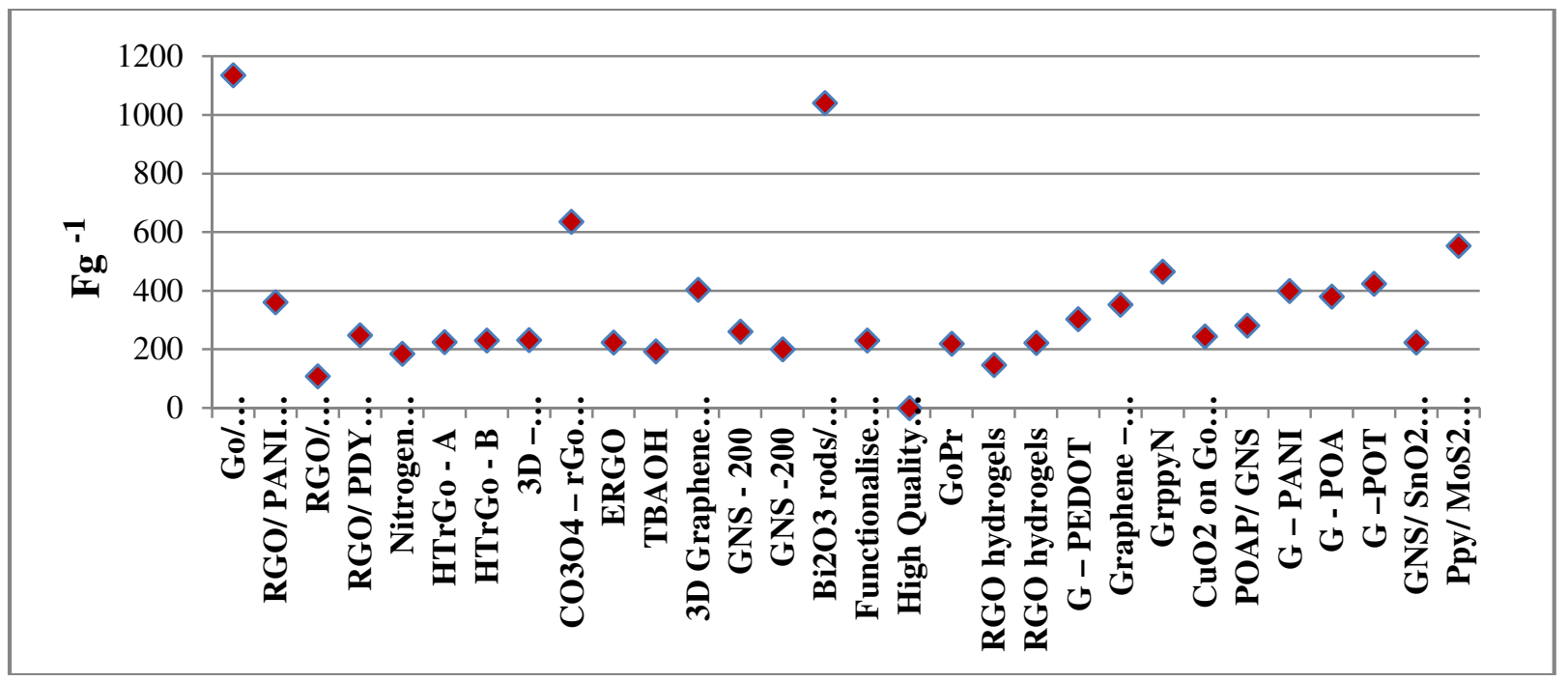

Fig.-3: Variation of Reported Specific Capacitance and Porous Carbon Derived from Various Graphene-Based Nanocomposites Precursors

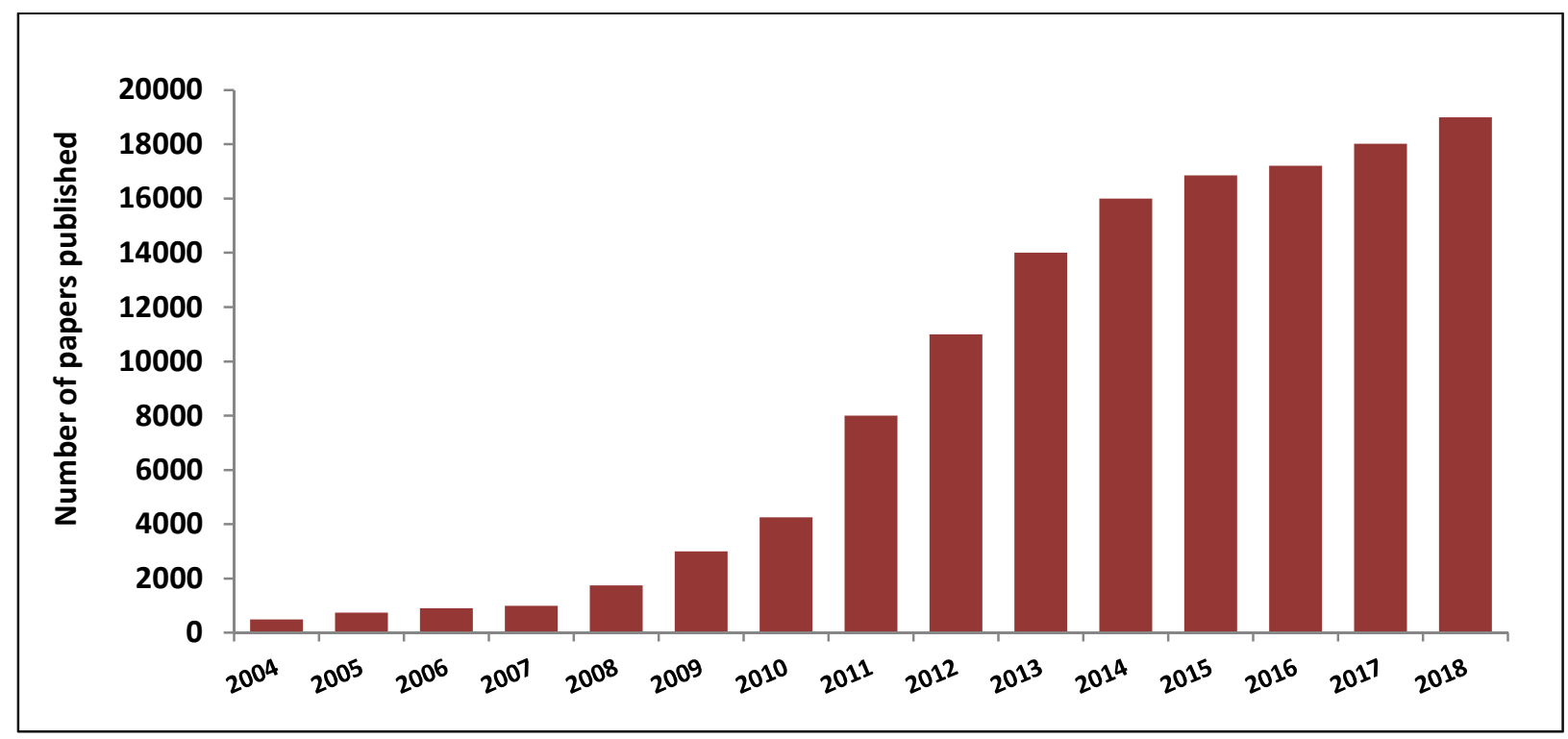

Fig.-4: The Annual Numbers of Publications of the Reported Graphene/Nanocomposites

Table-3: Advantages and Challenges Associated with Each Graphene Production Route ${ }^{79}$

\begin{tabular}{|c|c|c|}
\hline Production routes & Advantages & Challenges \\
\hline Graphite oxide & $\begin{array}{l}\text { High Yield } \\
\text { Down to single layer } \\
\text { Potentially scalable }\end{array}$ & $\begin{array}{l}\text { Potentially explosive process } \\
\text { Structural inhomogeneity } \\
\text { Batch-to-batch reproducibility }\end{array}$ \\
\hline $\begin{array}{l}\text { Liquid-phase } \\
\text { exfoliation }\end{array}$ & $\begin{array}{l}\text { Simple } \\
\text { Non-oxidative } \\
\text { Potentially scalable }\end{array}$ & $\begin{array}{l}\text { Low graphene yield } \\
\text { Low dispersibility } \\
\text { Low processability }\end{array}$ \\
\hline Electrochemical & $\begin{array}{l}\text { Cost-effectiveness } \\
\text { More Yield } \\
\text { A rich field of electrochemistry }\end{array}$ & $\begin{array}{l}\text { Electrical connectivity } \\
\text { graphite materials }\end{array}$ \\
\hline
\end{tabular}


RASĀYAN J. Chem.

Vol. 12 | No. 1 |214 - 231| January - March | 201

\section{CONCLUSION}

Nanocomposites based on graphene and polymers show promising growth in terms of technology and application. However, some key challenges need to be addressed to exploit the latent of nanocomposites of graphene with respect to synthesis methods, costs and applications.

- Some researchers used graphene as the only Nano filter, which showed better dispersion and properties compared to other Nanofillers in the applications of graphene-based nanocomposites recently,

- Graphite is relatively cheap and widely available worldwide and is the only main source (precursor) for the manufacture of graphene and Nano filters which can be derived from graphene. The current usage of industries is increased by using these graphene oxide-Nano fillers in its large-scale commercial products.

- Graphene compounds can be very advantageous in the chemical, biological and petroleum industries, as the ceramic and graphene compounds are more stable, highly recyclable and inert.

- Because of the great diversity, properties and uses of graphene, it has been proposed that applications based on nanocomposites are practical. These multifunctional graphene compounds together with reasonable price in the worldwide market very soon.

- Obviously, the work is far from complete, but with the quantity of concern in graphene when compared to carbon nanotubes; for example, it would not be surprising if the first graphene-based technologies available on the market come in the next decade. The obstacles must be overcome for the mass production and the quality of graphene.

- Through this study, it is clear that graphene and its derivatives show their potential as a successful candidate, strengthening the nanocomposites that are highly effective in using the energy storage system. Thus, the controlled alteration of graphite, GO and reduced graphene oxide are very significant to safeguard the properties of the material by increasing the application of graphene-based material of supercapacitor.

\section{ACKNOWLEDGMENT}

The authors wish to acknowledge the Avinashilingam Institute for Home Science and Higher Education for Women, Coimbatore, India, for providing the necessary facilities to carry out the studies.

\section{REFERENCES}

1. R. B. Kohakade, E. S. Kumar, R.W. Gaikwad, S. Raghu, R. A. Kalaivani, Rasayan J. Chem., 10(4),1151(2017), DOI:10.7324/RJC.2017.1041881.

2. R. Aarthi, K.C. Lalithambika, Rasayan J. Chem., 7(4), 340(2014)

3. V. Singh, D. Joung, L. Zhai, S Das, S. I. Khondaker, and S.Seal, Progressin Materials Science, 56, 1178 (2011), DOI: 10.1016/j.pmatsci.2011.03.003

4. X.Yang, X. Dou, A. Rouhanipour, L. Zhi, H. J. Rader, and K. Mullen, Journal of the American Chemical Society, 130, 4216 (2008), DOI: 10.1021/ja710234t

5. V. Sivasankar, E. S. Kumar, R. S. Babu, S. Raghu, R. A. Kalaivani, Rasayan J. Chem., 10(4),1232(2017), DOI: $10.7324 /$ RJC.2017.1041749

6. J. R. Potts, D. R. Dreyer, C. W. Bielawski and R. S. Ruoff, Polymer, 52, 5(2011), DOI:10.1016/j.polymer.2010.11.042.

7. R. C. Daniel, D. A. Benjamin, G. Nageswara et al., ISRN Condensed Matter Physics, 56(2012)

8. T. Lu, Y. Zhang, H. Li, L. Pan, Y. Li, and Z. Sun, ElectrochimicaActa., 55, 4170(2010), DOI: 10.1016/j.electacta.2010.02.095

9. Walt A. deHeer, C. Berger, X. Wuetal, Solid State Communications, 143,92 (2007), DOI: 10.1016/j.ssc.2007.04.023

10. Z. H. Ni, W. Chen, X. F. Fanetal, Physical Review B, 77, 115416 (2008), DOI: 10.1103/PhysRevB.77.115416

11. T. Seyller, A. Bostwick, K. V. Emtsev et al., Physica Status Solidi B, 245, 1436 (2008), DOI: 10.1002/ pssb.200844143 
RASĀYAN $J$. Chem.

Vol. 12 | No. 1 |214 - 231| January - March | 201

12. A. Mattausch and O. Pankratov, Physica Status Solidi B, 245, 1425 (2008), DOI: 10.1002/pssb.200844031

13. C. Berger, Z. Song, T. Li et al., Journal of Physical Chemistry B, 108, 19912 (2004), DOI: $10.1021 / \mathrm{jp} 040650 \mathrm{f}$

14. N. Li, Z. Wang, K. Zhao, Z. Shi, Z. Gu, and S. Xu, Carbon, 48, 255 (2010), DOI: 10.1016/ j.carbon.2009.09.013

15. S. Karmakar, N. V. Kulkarni, A. B. Nawale et al., Journal of Physics D, 42, 115201(2009), DOI: $10.1088 / 0022-3727 / 42 / 11 / 115201$

16. K. Singh, O. Anil, and S. K. Dhawan, Nano Composites-New Trends and Developments, F. Ebrahimi, UK, 37 (2012)

17. Y. Carissan and W. Klopper, Chem. Phys. Chem., 7, 1770 (2006), DOI:10.1002/cphc.200600171

18. L. Zhi and K. Mullen, Journal of Materials Chemistry, 18,1472 (2008), DOI: 10.1039/B717585J

19. C. Kim, B. Min, and W. Jung, Carbon, 47, 1610 (2009), DOI:10.1016/j.carbon.2009.02.025

20. L. Jiao, L. Zhang, X. Wang, G. Diankov, and H. Dai, Nature, 458, 877(2009), DOI: 10.1038/nature07919

21. D. V. Kosynkin, A. L. Higginbotham, A. Sinitskii et al., Nature, 458, 872(2009), DOI: 10.1038 /nature07872

22. A. Hirsch, Angewandte Chemie, 48, 6594 (2009), DOI: 10.1002/anie.200902534

23. I. Janowska, O. Ersen, T. Jacob et al., Applied Catalysis A, 371, 22 (2009), DOI: 10.1016/j.apcata.2009.09.013

24. S. Mohammadi, Z. Kolahdouz, S. Darbari, S. Mohajerzadeh, and N. Masoumi, Carbon, 52, 451 (2013), DOI:10.1016/j.carbon.2012.09.056

25. W. Zhang, J. Cui, C. Tao et al., Angewandte Chemie, 48, 5864(2009), DOI: 10.1002/ange.200902365

26. K. Sheng, Y. Xu, C. Li, and G. Shi, New Carbon Materials, 26,9 (2011), DOI: 10.1016/S18725805(11) 60062-0

27. Q. Liu, A. Ishibashi, T Fujigaya et al., Carbon, 11, 3424 (2011), DOI: 10.1016/ j.carbon.2011.04.038

28. B. E. Conway, Electrochemical Supercapacitors: Scientific Fundamentals and Technological Applications, Springer US, Boston, USA, (1999)

29. J. Xia, F. Chen, J. Li, N. Tao, Nat. Nanotechnology, 4,505(2009), DOI:10.1038/nnano.2009.177.

30. Y. Zhou, Q. L. Bao, A. L. Tang, Chem. Mater, 21, 2950 (2009), DOI: 10.1021/cm9006603

31. M. M. Hantel, T. Kaspar, R. Nesper, A. Wokaun, R. Kotz, Electrochem. Commun, 13, 90(2011), DOI:10.1016/j.elecom.2010.11.021

32. Yuyan Shao, Jun Wang, Mark Engelhard, Chongmin Wang and Yuehe Lin, J. Mater.Chem., 20,743(2010) DOI: 10.1039/b917975e

33. J. Yang and S. Gunasekaran, Carbon, 51, 36 (2013), DOI:10.1016/j.carbon.2012.08.003

34. Eunmi Choi, Jaekwang Kim, Yinhua Cui, Kyuho Choi, Yuan Gao, SeungheeHan,SungGyuPyo, and Songhun Yoon ,Electron Mater Lett, 13,324 (2017), DOI: 10.1007/s13391-017-1603-4

35. Y. Bai, R. Rakhi, W. Chen, and H. N. Alshareef, J. Power Sources, 233, 313 (2013), DOI:10.1016/j.jpowsour.2013.01.122

36. B. Dai, L. Fu, L. Liao, N. Liu, K. Yan, Y. Chen, and Z. Liu, Nano Res., 4, 434(2011), DOI: 10.1007/s 12274-011-0099-8

37. S. Y. Chee, H .L. Poh, C .K. Chua, F. Sanek, Z. Sofer, and M. Pumera, Chem. Phys., 14, 12794(2012), DOI: 10.1039/C2CP41462G

38. K. Zhang, L. Mao, L. L. Zhang, H. S. O. Chan, X. S. Zhaob, and J. Wu, J. Mater. Chem.21, 7302(2011) DOI: 10.1039/C1JM00007A

39. Shaoyi Lv, Feng Fu,Siqun Wang, Jingda Huang and La Hu,Electron. Mater. Lett, 11,633 (2015), DOI: $10.1007 / \mathrm{s} 13391-015-5023-\mathrm{Z}$

40. S. Some, Y. Kim, Y. Yoon, H. Yoo, S. Lee, Y. Park, and H. Lee, 3,1929 (2013), DOI: 10.1038/srep01929.

41. L. Chen, Z. Xu, J. Li, C. Min, L. Liu, X. Song, G. Chen, X. Meng, Mater. Lett, 65, 1229 (2011), DOI:10.1016/j.matlet.2011.01.063 


\section{RASĀYAN J. Chem.}

Vol. 12 | No. 1 |214 - 231| January - March | 201

42. M. J. Kiani, E. Akbari, F. R. Kooshkaki and A. Zeinalinezhad, Electron.Mater.Lett,12, 219 (2016), DOI: $10.1007 / \mathrm{s} 13391-015-5352-\mathrm{y}$

43. B. Zhao, P. Liu, Y. Jiang, D. Pan, H. Tao, J. Song, T. Fang, and W. Xu, J. Power Sources, 198, 423 (2012), DOI:10.1016/j.jpowsour.2011.09.074

44. M. J. McAllister, J. L. Li, D. H. Adamson, H. C. Schniepp, A. A. Abdala, J. Liu, M. H. Alonso, D.L. Milius, R. Car, R. K. Prudhomme, I. A. Aksay, Chem. Mater, 19, 4396 ( 2007), DOI: $10.1021 / \mathrm{cm} 0630800$

45. H.C. Schniepp, J. L. Li, M. J. McAllister, H. Sai, M. Herrera-Alonso, D. H. Adamson, R.K. Prudhomme, R. Car, D. A. Saville, I. A. Aksay, J. Phys. Chem. B, 110, 8535(2006), DOI: $10.1021 / \mathrm{jp} 060936 \mathrm{f}$

46. G. Peng, H. Song, X. H. Chen, Electrochem. Commun, 11, 1320(2009), DOI: 10.1016/ j.elecom. 2009.04.036

47. Q. Du, M. Zheng, L. Zhang, Y. Wang, J. Chen, L. Xue, W. Dai, G. Ji, J. Cao, Electrochim.Acta.,55, 3897 (2010), DOI:10.1016/j.electacta.2010.01.089

48. P. C. Lian, X. F. Zhu, S. Z.Liang, Z. Li, W. S. Yang, H. H. Wang, Electrochim. Acta, 55, 3909 (2010), DOI:10.1016/j.electacta.2010.02.025

49. S. Stankovich, D. A. Dikin, R. D. Piner, K. A. Kohlhaas, A. Kleinhammes, Y. Jia, Y. Wu, S.T. Nguyen, R. S. Ruoff, Carbon, 45, 1558 (2007), DOI:10.1016/j.carbon.2007.02.034

50. S. Park,R.S.Ruoff,Nat.Nanotechnology,4, 217 (2009)

51. Y. W. Zhu, S. Murali, M. D. Stoller, K. J. Ganesh, W. W. Cai, P. J. Ferreira, A. Pirkle, R. M. Wallace, K. A. Cychosz, M. Thommes, D. Su, E.A. Stach, R.S. Ruoff, Science, 332,1537(2011), DOI: $10.1126 /$ science. 1200770

52. M. F. El-Kady, V. Strong, S. Dubin and R. B. Kaner , Science,335 ,1326 (2012), DOI: 10.1126/science. 1216744

53. Jeong K.Lee, Kurt B. Smith, Cary M. Hayner and Harold H. Kung, Chem. Commun., 46, 2025( 2010) DOI: $10.1039 / \mathrm{B} 919738 \mathrm{~A}$

54. Viet Hung Pham, Tesfaye Gebre and James H. Dickerson, Nanoscale, 14, (2015), DOI: 10.1021/ acs.jpcc.6b00326

55. V. H. Luan, H. N. Tien, L. T. Hoa, N.T.M. Hien, E.-S.Oh, J. Chung, E. J. Kim, W. M. Choi, B.-S. Kong, and S. H. Hur ,J.Mater. Chem. A, 1, 208 (2013), DOI: 10.1039/C2TA00444E

56. H. J. Shin, K. K. Kim, A. Benayad, S.-M.Yoon, H. K. Park, I.-S.Jung, M. H. Jin, H.K. Jeong, J.M. Kim, J.-Y.Choi, Y. H. Lee, Adv. Funct. Mater, 19, 1987 (2009), DOI: 10.1002/adfm.200900167

57. V. H. Pham, T. Gebre and J. H. Dickerson, ,Nanoscale,7,5947 (2015), DOI:10.1039/C4NR07508K

58. K. Torvinen, S. Lehtimaki, J. T. Keranen, J. Sievanen, J. Vartiainen, E. Hellen, D. Lupoand S. Tuukkanen, Electron. Mater. Lett., 11,1040 (2015), DOI: 10.1007/s13391-015-5195-6

59. Q. Zhang, Y. Li, Y. Feng, and W. Feng, Electrochim. Acta, 90, 95 (2013), DOI: 10.1016/j.electacta.2012.11.035

60. J. Zhang and X. Zhao, J. Phys. Chem. C, 116, 5420 (2012), DOI: 10.1021/jp211474e

61. F. Alvi, M. K. Ram, P. A. Basnayaka, E. Stefanakos, Y. Goswami, and A. Kumar, Electrochimica Acta, 56, 9406(2011), DOI:10.1016/j.electacta.2011.08.024

62. H.Gomez, M.K.Ram, F.Alvi, P.Villalba, E.Stefanakos, and A.Kumar, Journal of Power Sources,196, 4102 (2011), DOI:10.1016/j.jpowsour.2010.11.002

63. Y. Zhan, X. Yang, H. Guo, J. Yang, F. Meng, and X. Liu, Journal of Materials Chemistry, 22, 5602 (2012), DOI: 10.1039/C2JM15780B

64. S. Sahoo, S. Dhibar, G. Hatui, P. Bhattacharya, and C. K. Das, Polymer,54, 1033(2013), DOI: 10.1016/j.polymer.2012.12.042

65. Q. Liu, O. Nayfeh, M. H. Nayfeh, and T. YauS, NanoEnergy, 2, 133 (2013), DOI: 10.1016/ j.nanoen.2012.08.007

66. H. Heli, H. Yadegari, and A. Jabbari,Materials Chemistry and Physics, 134, 21(2012), DOI: 10.1016 /j.matchemphys.2012.02.065

67. P. A. Basnayaka, M. K. Ram, E. Stefanakos, and A. Kumar, Electrochimica Acta, 92, 376(2013), DOI: $10.1016 /$ j.electacta.2013.01.039 
RASĀYAN J. Chem.

Vol. 12 | No. 1 |214 - 231| January - March | 201

68. Y. Li, H. Peng, G. Li, and K. Chen, European Polymer Journal, 48, 1406(2012), DOI: 10.1016/j.eurpolymj.2012.05.014

69. G. Ma, H. Peng, J. Mu, H. Huang, X. Zhou, and Z. Lei, Journal of Power Sources, 229, 72 (2013), DOI: $10.1016 / j$ j.jpowsour.2012.11.088

70. L.J.ie, J. F. Wu, C. M. Chen, C. M. Zhang, L. Wan, J.-L. Wang, Q.Q. Kong, C.-X. Lv, K.X. Li, and G.-H. Sun, J. Power Sources, 242, 148(2013), DOI:10.1016/j.jpowsour.2013.05.081

71. E. Choi, D. Kim, I. Lee, S. J. Chae, A. Kim, S. G. Pyo, and S. Yoon, Electron. Mater. Lett,11, 836 (2015), DOI: $10.1007 / \mathrm{s} 13391-015-4493-3$

72. X. Mu, X. Liu, K. Zhang, J. Li, J. Zhou, E. Xie, and Z. Zhang, Electron. Mater. Lett., 12, 296 (2016), DOI: $10.1007 / \mathrm{s} 13391-015-5382-5$

73. D. Maruthamani, S. Vadivel, M. Kumaravel, B. Saravanakumar, Bappi Paul, Siddhartha Sankar Dhar, Aziz Habibi-Yangjeh , A. Manikandan , Govindarajan Ramadoss, Journal of Colloid and Interface Science, 498,449(2017), DOI: 10.1016/j.jcis.2017.03.086

74. D .Ratih, R. Siburian and Andriayani, Rasayan J. Chem., 11,1649(2018), DOI: 10.31788/ RJC.2018.1145007

75. K. Narasimharao, G. Venkata Ramana, D. Sreedhar and V. Vasudevarao, J. Material Sci. \& Eng., 5, 6(2016), DOI: 10.4172/2169-0022.1000284

76. Z. Ji, J. Wu, X. Shen, H. Zhou, H. Xi, J. Mater. Sci.,46, 1190 (2011), DOI: 10.1007/s10853-0104892-7

77. B. Yuan, C. Xu, D. Deng et al., Electrochimica Acta, 88, 708(2013), DOI: 10.1016/j.electacta.2012.10.102

78. R. B. Rakhi and H. N. Alshareef, Journal of Power Sources,196, 8858(2011), DOI: 10.1016/j.jpowsour.2011.06.038

79. Yu Lin Zhong, Zhiming Tian, George P. Simon and Dan Li, Materials Today, 18, 73(2015), DOI: 10.1016/j.mattod.2014.08.019

80. L. Nyholm, L. Nystroom, A. Mihranyan and M. Stromme, Adv. Mater., 23, 3751(2011), DOI: 10.1002/adma.201004134

[RJC-5039/2018] 